\title{
La contaminación atmosférica de la ciudad de México en escala megalopolitana*
}

\author{
Gustavo Garza** \\ Fernando Aragón***
}

El propósito de este artículo es analizar los niveles de contaminación atmosférica en el Área Metropolitana de la Ciudad de México, las fuentes que la producen, el impacto sobre la salud de la población y las políticas implementadas hasta ahora para intentar reducir la gravedad del problema. Se desarrolla como tesis central que estas políticas ahora están lejos de resolver la elevada contaminación atmosférica del valle de México y, lo que es más grave, se vislumbra nítidamente que el problema del medio ambiente adquirirá una magnitud megalopolitana que implicará el deterioro en cadena de los valles de las ciudades vecinas de Toluca, Cuernavaca, Puebla, Tlaxcala y Querétaro. Al considerar la gravedad de este hecho, que amenazaría seriamente la capacidad de autorregeneración de los ecosistemas de estas metrópolis y rompería la armonía básica entre población y naturaleza, es urgente diseñar acciones específicas de política urbano-regional que impidan que esto ocurra.

El Área Metropolitana de la Ciudad de México, con 15 millones de habitantes en 1990, constituye la quinta ciudad más poblada del mundo después de Tokio, Nueva York, São Paulo y Seúl. El tejido de la urbe ocupa un área de $1400 \mathrm{~km}^{2}$ donde vive $30.3 \%$ de la población urbana del país y se genera $35 \%$ del producto interno bruto nacional. La crisis económica de los años ochenta hace que la problemática urbana de la capital mexicana aumente considerablemente: se elevan el desempleo y el subempleo; aumenta el déficit habitacional; se extienden las colonias proletarias hacia la periferia norte y este; se agudizan las carencias de servicios urbanos (agua, drenaje, electricidad, alumbrado, vigilancia, recolección de basura, etc.); la delincuencia y la violencia se propagan, y la contaminación del ecosistema llega a niveles críticos; en febrero de 1988 se declaró una situación de "contingencia II", que im-

\footnotetext{
* Los autores agradecen los valiosos comentarios de Adrián Fernández a la primera versión de este documento. Extendemos nuestra gratitud a Gabriel Quadri, Víctor Hugo Páramo y Guadalupe de la Luz, de la Dirección General de Normatividad Ambiental del Instituto Nacional de Ecología, por su importante apoyo al proporcionarnos gran parte de la información utilizada.

** Profesor-investigador del Centro de Estudios Demográficos y de Desarrollo Urbano de El Colegio de México.

*** Universidad de las Américas, Puebla.
} 
plicó la reducción a 50\% de la actividad industrial y el cierre de las escuelas.

El objetivo de este documento es, precisamente, analizar la problemática ambiental sistematizando la información existente sobre los niveles de la contaminación atmosférica de la ciudad de México, las fuentes que la producen, el impacto sobre la salud de la población y las políticas para intentar reducirla. A manera de conclusión, finalmente, se advierte que de igual manera que en el valle de México, la degradación ecológica tenderá a ocurrir en los valles adyacentes si no se establecen rigurosas políticas para evitarlo. El análisis principia en 1986, cuando se inicia la medición sistemática de los niveles de contaminación, y termina en junio de 1994, aunque se presentan elementos prospectivos de la expansión urbana hasta el año 2010.

\section{La megalópolis de la ciudad de México}

La ciudad de México se localiza en una cuenca de $9560 \mathrm{~km}^{2}$ de superficie que tiene una altitud de $2240 \mathrm{msnm}$ y se sitúa entre los paralelos $19^{\circ}-20^{\circ}$ de latitud norte y los meridianos $98^{\circ}-99^{\circ}$ de longitud oeste. La abundancia de agua cristalina proveniente de sus montañas formó hace siglos tres lagos. En un islote del lago de Texcoco, los aztecas fundaron la gran ciudad de Tenochtitlan en 1324 donde, sobre sus ruinas, el conquistador español Hernán Cortés inició en 1521 la construcción de la "Muy Noble, Insigne y Muy Leal e Imperial Ciudad de México".

En 1994 la ciudad de México cumplió 473 años de existencia, aunque su carácter metropolitano principia a mediados del siglo XX. En 1900 era una localidad media de 344000 habitantes. Para 1930 eleva su población a un millón de personas y a 2.9 millones en 1950. Hasta ese año la urbe no rebasaba los límites del Distrito Federal, pero a partir de 1950 inició su crecimiento por el norte hacia los municipios del Estado de México, uno de los 31 estados que forman la República mexicana. Surge, técnicamente hablando, el Área Metropolitana de la Ciudad de México, que en este trabajo llamaremos, para simplificar, ciudad de México o capital del país, aunque siempre nos referiremos a su área metropolitana.

Entre 1950 y 1980, la ciudad de México creció aceleradamente hasta alcanzar 12.6 millones de habitantes en este último año. En los ochenta redujo su dinámica de crecimiento como reflejo de la profunda crisis económica que experimentó al desplomarse su participación en la producción industrial nacional de $43.3 \%$ en 1980 a $32.1 \%$ en 1988 . No obstante lo anterior, en 1990 alcanza 
una población de 15 millones de habitantes, localizados en el Distrito Federal y en 27 municipios del Estado de México.

El paso de una localidad de 344000 habitantes en 1900 a una superconcentración de 15 millones en 1990 implicó el surgimiento de graves problemas ambientales por las condiciones geográficas y climatológicas de la cuenca de México: la menor cantidad de oxígeno por su altitud; elevada incidencia solar que produce gran reactividad atmosférica; orografía y patrón de vientos que agudiza las inversiones térmicas y trasladan con mayor frecuencia los contaminantes al poniente y sur de la urbe.

En las postrimerías del siglo xx el Área Metropolitana de la Ciudad de México se ha traslapado con el Área Metropolitana de la Ciudad de Toluca, hecho que ha dado lugar a un conglomerado polinuclear que en la terminología de la "ciencia regional" se le denomina megalópolis. Se estima que en las próximas dos décadas la megalópolis de la ciudad de México incorporará a las zonas metropolitanas de Cuernavaca, Puebla y Querétaro, conformando una región urbana polinuclear. ¿Podrá esta concentración tener un desarrollo sustentable?

Tendencias de la contaminación atmosférica, 1986-1994

La gravedad de la contaminación atmosférica en la ciudad de México se evidenció a principios de los años setenta cuando se publicaron las primeras investigaciones que alertaban sobre el problema (Bravo, 1973; Escobar, 1973; Vizcaíno Murray, 1975; Márquez Mayaudón, 1978; SAHOP, 1978). En la década de los ochenta la expansión demográfica y la concentración económica aceleran la degradación de la atmósfera del valle de México, llamado alguna vez poéticamente "la región más transparente del aire". La medición de contaminantes se inicia en los años sesenta cuando se instalaron catorce estaciones de monitoreo de azufre, las cuales aumentaron a 22 en los años setenta, aunque se utilizaban esporádicamente. Es hasta la segunda mitad de los ochenta cuando principia la medición de otros contaminantes y se toman acciones más rigurosas por el gobierno para combatirlos, como veremos posteriormente. Este apartado sistematiza la tendencia de los niveles de contaminación atmosférica en la ciudad de 1986 a 1994, evaluando su gravedad y, posteriormente, se verá el resultado de las políticas para combatirlos.

En 1982 la Secretaría de Salubridad y Asistencia estableció los criterios de calidad del aire para los principales contaminantes atmosféricos con base en las normas sugeridas por la Organización 
Mundial de la Salud (véase el cuadro 1). Los principales contaminantes del aire en la ciudad de México, exceptuando el ozono, son los que existen en la gran mayoría de las grandes metrópolis: ozono $\left(\mathrm{O}_{3}\right)$, partículas suspendidas totales (PST), óxidos de nitrógeno $\left(\mathrm{NO}_{\mathrm{x}}\right)$; óxidos de azufre ( $\mathrm{SO}_{\mathrm{x}}$ ), monóxido de carbono (CO), plomo $(\mathrm{Pb})$ y otros tóxicos. Para su medición, actualmente se cuenta con una Red Automática de Monitoreo Atmosférico constituida por 32 estaciones y una Red Manual formada por 19. Mientras las estaciones automáticas miden los niveles de ozono, monóxido de carbono, bióxido de azufre, bióxido de nitrógeno y óxido de nitrógeno, así como parámetros meteorológicos (temperatura, húmedad, viento, etc.), las manuales calculan las partículas suspendidas y el plomo (Comisión Metropolitana para la Prevención y Control de Contaminación en el valle de México, 1994: 8-9). ${ }^{1}$ Para facilitar la comprensión general del nivel de cada contaminante y su relación con la norma establecida, las autoridades diseñaron un Índice Metropolitano de la Calidad del Aire (IMECA), según el cual 100 IMECAS corresponden al valor de la norma de calidad para cada contaminante. Para el caso del ozono, por ejemplo, 100 IMECAS equivalen a 0.11 partes por millón (ppm) de ozono en una hora, 200 IMECAS a $0.22 \mathrm{ppm}$ y, así, sucesivamente. ${ }^{2}$

CUADRO 1

Ciudad de México: normas de calidad del aire

\begin{tabular}{lll}
\hline \multicolumn{1}{c}{ Contaminante } & \multicolumn{1}{c}{ Norma } \\
\hline Monóxido de carbono & $(\mathrm{CO})$ & $11 \mathrm{ppm}$ en 8 horas \\
Dióxido de azufre & $\left(\mathrm{SO}_{3}\right)$ & $0.13 \mathrm{ppm}$ en 24 horas \\
Dióxido de nitrógeno & $\left(\mathrm{NO}_{2}\right)$ & $0.21 \mathrm{ppm}$ en 1 hora \\
Ozono & $\left(\mathrm{O}_{3}\right)$ & $0.11 \mathrm{ppm}$ en 1 hora \\
Partículas menores de & & \\
$\quad$ 10 micrómetros & $(\mathrm{PM}-10)$ & $150 \mu \mathrm{g} / \mathrm{m}^{3}$ en 24 horas \\
Partículas suspendidas totales & $(\mathrm{PST})$ & $275 \mu \mathrm{g} / \mathrm{m}^{3}$ en 24 horas \\
Plomo & $(\mathrm{Pb})$ & $1.5 \mu \mathrm{g} / \mathrm{m}^{3}$ promedio trimestral \\
\hline
\end{tabular}

Fuente: DDF, Programa integral contra la contaminación atmosférica, México, D.F. (s.f.: 29).

a La abreviatura ppm significa partes por millón y $\mu \mathrm{g} / \mathrm{m}^{3}$ microgramos por metro cúbico.

b La fuente señala 13 ppm en 8 horas, pero se redujo a 11 ppm en 1993.

1 Nadie ha intentado ponerle siglas, por lo que para simplificar en adelante se le denominará "Comisión Metropolitana".

2 El procedimiento para la conversión de partes por millón o microgramos por metro cúbico de contaminantes en IMECAs, o viceversa, se presenta en Comisión Metropolitana, diciembre, 1993: VI-II. 


\section{Formación de ozono}

El ozono es producto de la disociación fotoquímica de los óxidos de nitrógeno y otros compuestos orgánicos reactivos emitidos a la atmósfera por el uso de solventes y la combustión de hidrocarburos. Por la latitud y altitud de la ciudad de México las radiaciones ultravioleta son más intensas, lo que tiende a estimular la formación de ozono.

La norma establecida por el gobierno mexicano a partir de la cual se considera al ozono como dañino para la salud de la población es de $\mathbf{0 . 1 1}$ ppm en una hora, mientras que en Estados Unidos es de $0.12 \mathrm{ppm}$ y la Organización Mundial de la Salud recomienda $0.10 \mathrm{ppm}$.

Conforme la norma mexicana, los niveles de contaminación por ozono en la ciudad de México se elevaron dramáticamente entre 1986 y junio de 1994. Considerando las cinco zonas geográficas en que se divide la ciudad, el número de días en que se sobrepasó la norma de ozono en 1986 va de $6.8 \%$ en la noreste y $54.8 \%$ en la suroeste, con un promedio de 19.7\% (véase el cuadro 2). En 1994 la zona noreste continúa siendo la menos contaminada, aunque $\mathbf{8 1 . 1 \%}$ de los días transcurridos hasta el 13 de junio sobrepasaron la norma, y en la zona suroeste el porcentaje ascendió a $89.6 \%$. En promedio, para 1994 las cinco zonas tuvieron $88.5 \%$ de días considerados sobre la norma (véase el cuadro 2). En la actualidad, prácticamente todos los días del año sobrepasan en $200 \%$ la norma existente de ozono, acercándose peligrosamente a los 300 IMECAS, a partir de los cuales se declara el estado de "contingencia II".

En los meses invernales de diciembre a febrero, las inversiones térmicas en la atmósfera del valle de México son más frecuentes, con lo que se acentúa el problema de la contaminación al dificultarse la dispersión de los contaminantes. En enero y febrero el promedio de las concentraciones de ozono en la ciudad no sólo sobrepasa con mucho la norma de $0.11 \mathrm{ppm}$, sino que tiende a elevarse. En la gráfica 1 se observa cómo en 1989 el promedio de la concentración de ozono en estos meses fue de 0.17 , esto es, $55 \%$ mayor que la norma, y se elevó hasta $0.21 \mathrm{ppm}$ en 1993 , superándola en 90 por ciento.

A partir de 1989 se instrumentaron importantes medidas gubernamentales para reducir la contaminación atmosférica de la capital mexicana, las cuales en el caso del ozono han resultado totalmente infructuosas. Considerando el crecimiento futuro de la urbe y su transformación en un conglomerado megalopolitano, el problema de la contaminación atmosférica podría quedar fuera de control, amenazando la sobrevivencia de aquéllas. 


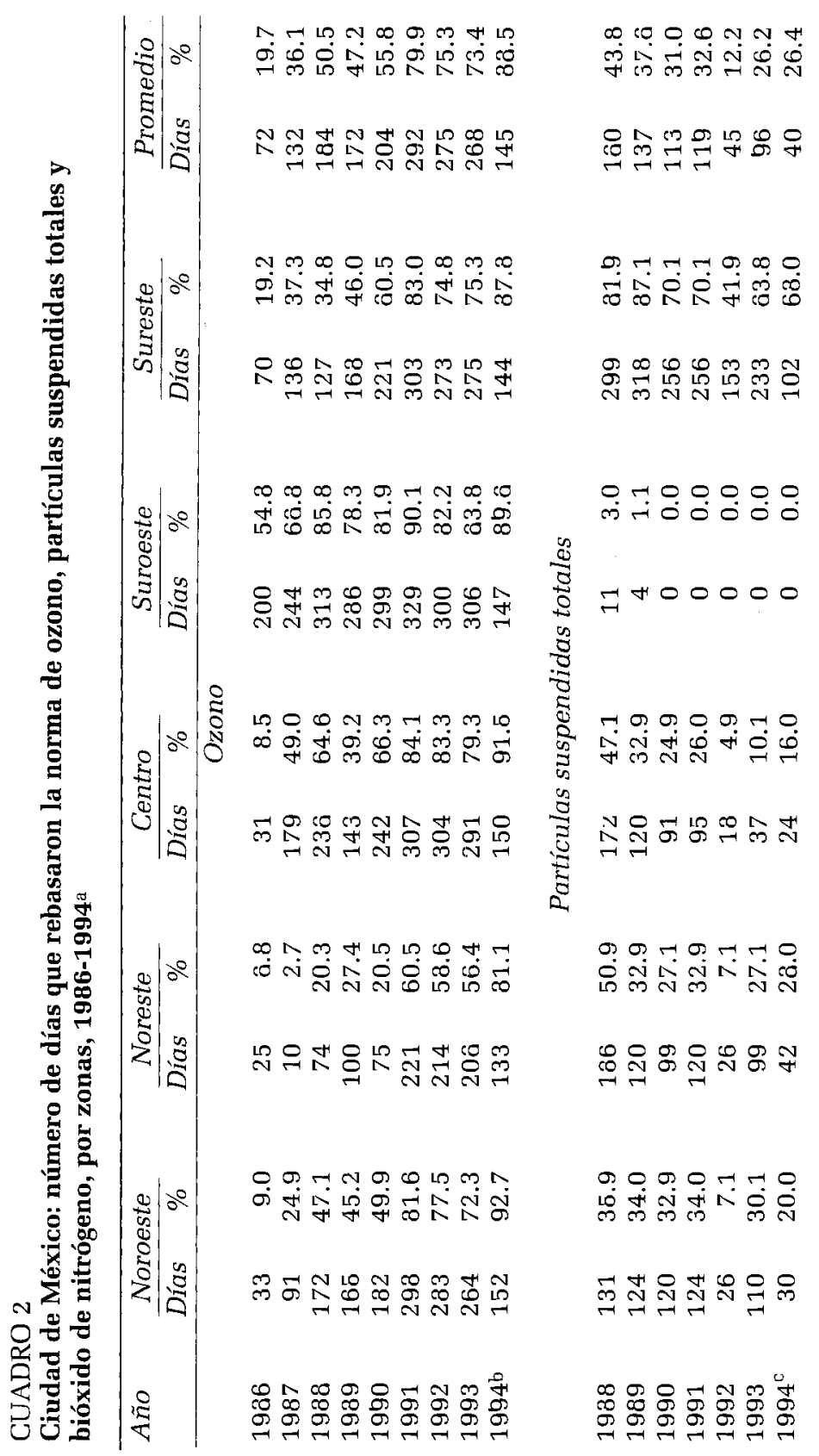




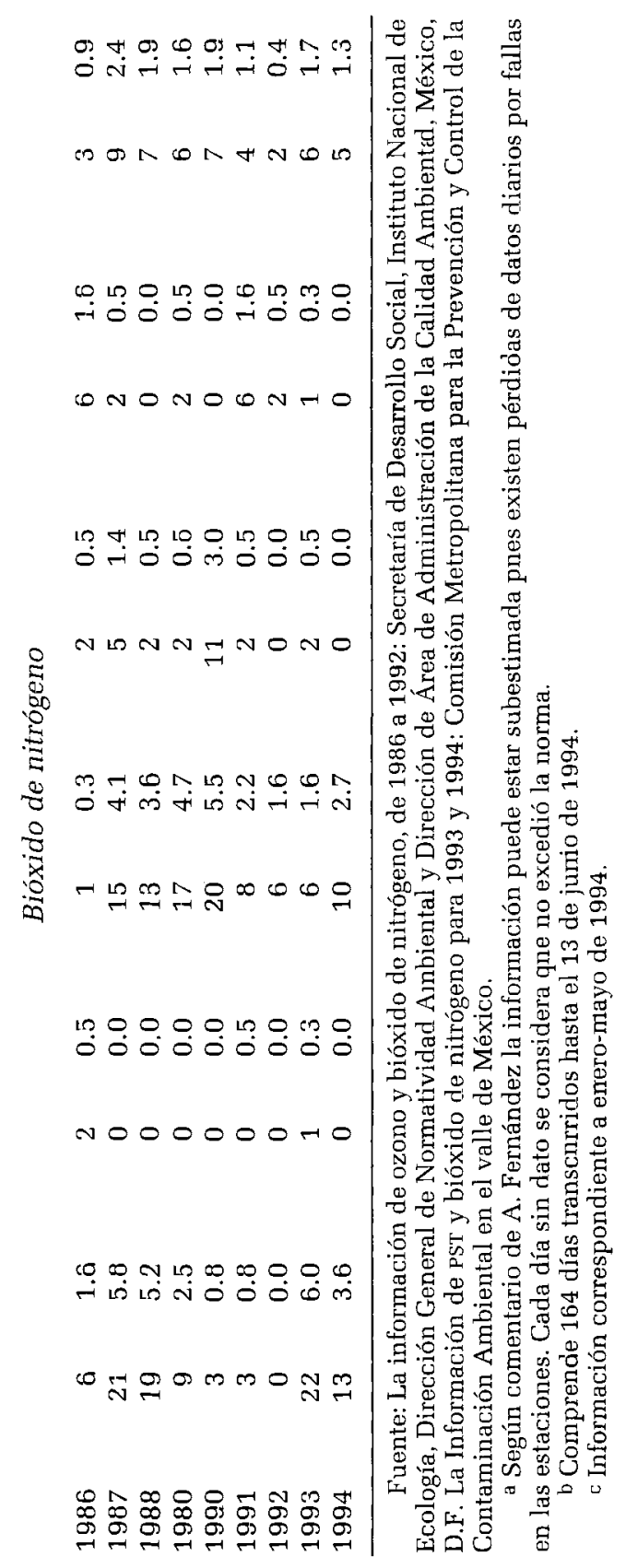


GRÁFICA 1

Ciudad de México: concentración de ozono, bióxido de azufre y bióxido de nitrógeno, enero-febrero, 1989-1993 (PPM)

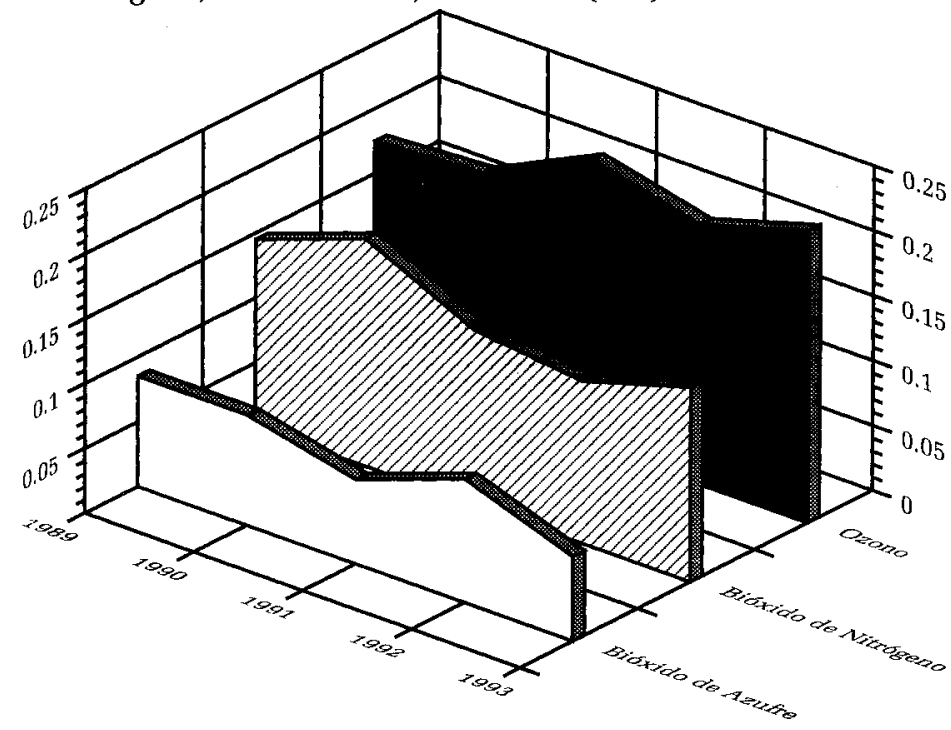

Fuente: Ingeniería y Gestión Ambiental, "Calidad del aire en la ciudad de México", reporte mensual, México, D. F., febrero de 1993.

\section{Partículas suspendidas}

Las partículas suspendidas son principalmente los aerosoles, vapores orgánicos y metálicos, elementos de la combustión y polvos. Las partículas más pequeñas, con diámetros menores de 10 micrometros (PM-10), son las más dañinas para la salud pues penetran en los pulmones. Las principales partículas del tipo PM-10 son aquellas producidas por la combustión de diesel, aerosoles orgánicos, sulfatos y nitratos formados por reacciones fotoquímicas.

La medición de las partículas suspendidas se hace sólo esporádicamente (de una a seis veces al mes) y para las PM-10 se inicia hasta 1991 (Departamento del Distrito Federal, 1991: 2-10; Ingeniería y Gestión Ambiental, febrero, 1993: 7). En relación con las partículas suspendidas totales (PST), para 1988 los niveles excedían la norma establecida de $275 \mu \mathrm{g} / \mathrm{m}^{3}$ en $43.8 \%$ de los días muestreados, aunque presentan grandes diferencias por zonas geográficas: en la sureste $81.9 \%$ de los días la sobrepasaban y en la suroeste sólo 
$3.0 \%$ (véase el cuadro 2). Las acciones realizadas para enfrentar este problema, que se verán posteriormente, tuvieron efectos positivos, pues para 1993 el promedio general de días con valores superiores a la norma disminuyó a $26.2 \%$, en la zona sureste a $68.0 \%$ y en la suroeste a cero. De enero a mayo de 1994 estos porcentajes se mantuvieron con un nivel semejante, indicando que en uno de cada cuatro días el nivel de las PST superó el máximo recomendado de 275 $\mu \mathrm{g} / \mathrm{m}^{3}$. En las zonas industriales localizadas en el noreste de la ciudad, sin embargo, se han registrado niveles de 1100 a $1300 \mathrm{\mu g} / \mathrm{m}^{3}$, esto es, entre 300 y $370 \%$ superiores a la norma (Departamento del Distrito Federal, 1991: 2-11). En síntesis, aunque se observa hasta 1993 una tendencia a reducir los niveles de este contaminante, sus magnitudes aún son considerables y podrían elevarse si continúa la erosión de los municipios semiáridos del Estado de México.

\section{Bióxido de nitrógeno}

Los óxidos de nitrógeno $\left(\mathrm{NO}_{\mathrm{x}}\right)$ se producen principalmente por la combustión de productos derivados del petróleo. Los niveles de este contaminante deben vigilarse cuidadosamente, pues es uno de los componentes precursores del ozono.

Los niveles de bióxido de nitrógeno $\left(\mathrm{NO}_{2}\right)$ en la atmósfera de la ciudad de México en 1986 sólo rebasaban la norma establecida de $0.21 \mathrm{ppm}$ en un promedio de $0.9 \%$ días al año, variando entre $0.3 \%$ en la zona centro y $1.6 \%$ en la noroeste y sureste (véase el cuadro 2). Antes de que se iniciaran las acciones más significativas contra la contaminación en 1989, este contaminante no representaba un problema agudo para la población, pero su nivel alcanzado se mantuvo (véase la gráfica 1). Para 1993 el número promedio de días sobre la norma representó $1.7 \%$, duplicando el porcentaje de 1986 pero siendo aún reducido. Se observa, sin embargo, una mayor desigualdad entre zonas geográficas, pues mientras la noroeste tuvo $6.0 \%$, la noreste y sureste únicamente 0.3 por ciento.

En los meses invernales es cuando más se sobrepasa la norma; esta situación disminuye significativamente en la temporada de lluvias de junio a septiembre. En diciembre de 1993, por ejemplo, tres de las cinco zonas presentaron un nivel máximo por arriba de la norma (véase el cuadro 3).

Puede concluirse que de 1986 a mediados de 1994 ocurre un ligero aumento del número de días con niveles de bióxido de nitrógeno sobre la norma. Aunque los niveles absolutos se mantienen, al parecer no constituyen un peligro para la salud de la población. 
CUADRO 3

Ciudad de México: niveles máximos de bióxido de nitrógeno, bióxido de azufre y monóxido de carbono, por zonas, diciembre de 1993

\begin{tabular}{|c|c|c|c|c|c|c|}
\hline \multirow[b]{2}{*}{ Zona } & \multicolumn{2}{|c|}{$\begin{array}{c}\text { Bióxido de } \\
\text { nitrógeno }\end{array}$} & \multicolumn{2}{|c|}{$\begin{array}{c}\text { Bióxido de } \\
\text { azufre }\end{array}$} & \multicolumn{2}{|c|}{$\begin{array}{l}\text { Monóxido } \\
\text { de carbono }\end{array}$} \\
\hline & IMECA & $p p m^{a}$ & IMECA & $p p m^{\mathrm{b}}$ & IMECA & $p p m^{\mathrm{c}}$ \\
\hline Norma & 100 & 0.21 & 100 & 0.13 & 100 & 11.0 \\
\hline Noroeste & 119 & 0.29 & 37 & 0.05 & 54 & 7.0 \\
\hline Noreste & 86 & 0.18 & 49 & 0.06 & 46 & 6.0 \\
\hline Centro & 111 & 0.26 & 38 & 0.05 & 57 & 7.4 \\
\hline Suroeste & 116 & 0.28 & 33 & 0.04 & 40 & 5.2 \\
\hline Sureste & 91 & 0.19 & 28 & 0.04 & 44 & 5.7 \\
\hline
\end{tabular}

Fuente: Comisión Metropolitana para la Prevención y Control de la Contaminación Ambiental en el Valle de México, diciembre de 1993: VI-2 y 3.

a Partes por millón en 1 hora.

b Partes por millón en 8 horas.

c. Partes por millón en 24 horas.

\section{Óxidos de azufre}

Los óxidos de azufre $\left(\mathrm{SO}_{\mathrm{x}}\right)$ son emitidos por el uso de combustibles con azufre, como el gasóleo y el diesel. Su componente principal es el bióxido de azufre $\left(\mathrm{SO}_{2}\right)$ que es un gas incoloro que reacciona con una variedad de partículas del aire y gotas de agua para formar sulfatos, aerosoles y lluvia ácida.

Los niveles de bióxido de azufre en la atmósfera de la ciudad de México se han mantenido por debajo de la norma de $0.13 \mathrm{ppm}$ en 24 horas y muestran una tendencia estable (véase la gráfica 1). En 1986, sin embargo, en la zona noreste se presentaron seis días por encima de la norma de bióxido de azufre y uno en la sureste, haciendo un promedio de $0.4 \%$. Para 1993 y 1994 ninguna zona observa días sobre la norma de este contaminante, lo que indica que las acciones específicas para reducirlo han sido eficaces (véase el cuadro 4).

En diciembre de 1993 las cinco zonas geográficas de la ciudad de México presentaron niveles de bióxido de azufre al menos $50 \%$ debajo de la norma, aunque con ligeras diferencias entre ellas puesto que la noreste tuvo $0.06 \mathrm{y}$ las suroeste y sureste 0.04 ppm (véase el cuadro 3 ). 


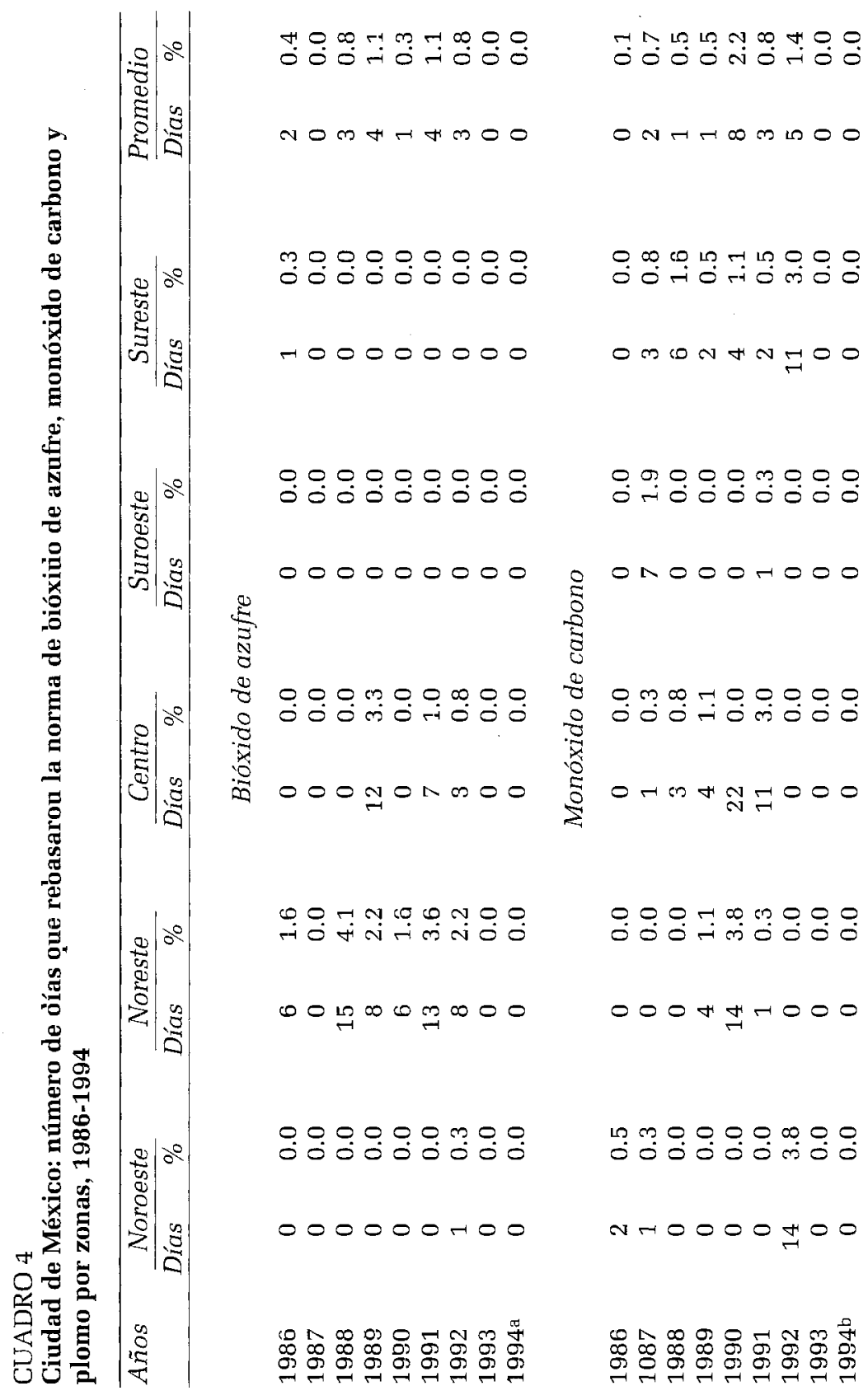




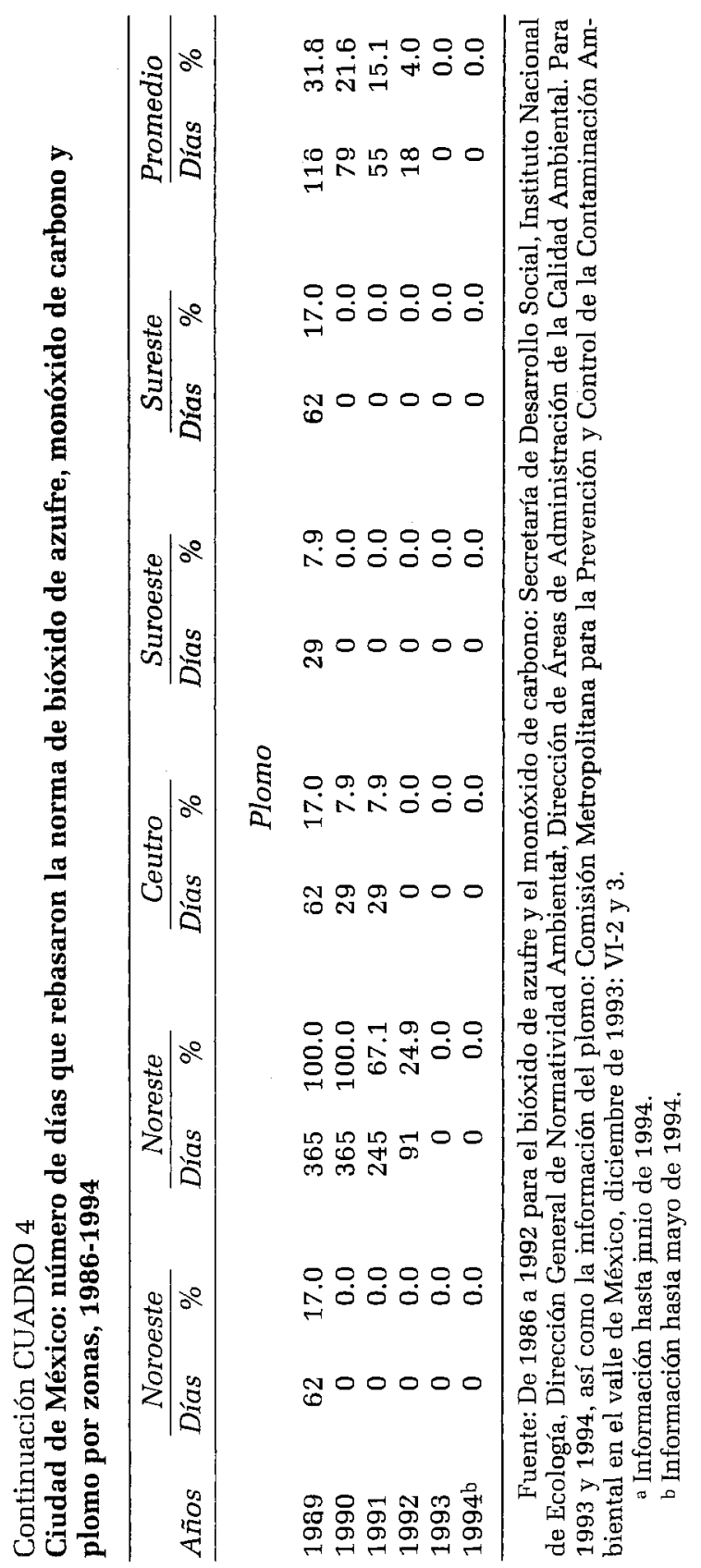




\section{Monóxido de carbono}

El monóxido de carbono (CO) es un gas incoloro, inodoro e insípido, algo más ligero que el aire, producido principalmente por la combustión incompleta de gasolina en los vehículos automotores. De 1982 a 1992 la norma establecida para este contaminante fue de $13 \mathrm{ppm}$ en ocho horas, pero se ha propuesto como nueva norma 11 partes por millón.

Desde 1986 el CO, al igual que el $\mathrm{SO}_{2}$ y el $\mathrm{NO}_{2}$, pocos días sobrepasa la norma anterior. En ese año sólo la región noroeste tuvo algunos días en esa situación, y resultó un escaso promedio general de $0.1 \%$ de días. Éste alcanzó en 1990 su máximo nivel con $2.2 \%$, para disminuir a cero en los años recientes (véase el cuadro 4). En diciembre de 1993 en ninguna de las cinco zonas de la ciudad se superó la norma establecida (véase el cuadro 3 ).

Considerando que el monóxido de carbono se emite muy cerca del suelo y que las calles están delimitadas con edificaciones, este contaminante presenta un patrón de lenta dispersión que produce una concentración en el ambiente donde se ubican las estaciones de monitoreo varias veces menor a la existente al nivel de la calle, por lo que tales estaciones no miden el verdadero grado a que está expuesta la población (Departamento del Distrito Federal, 1991: 2-14). A este respecto, se ha demostrado que los niveles del CO dentro de los vehículos son superiores 4.2 veces en promedio a los medidos en las estaciones de monitoreo (Fernández, 1993). Esto significa que el CO constituye un factor de riesgo para la salud de la población capitalina, especialmente para los estratos ocupacionales que laboran y circulan frecuentemente en la vía pública.

\section{Plomo}

La presencia de partículas de plomo $(\mathrm{Pb})$ en el medio ambiente se debe fundamentalmente a la combustión de gasolina con plomo, aunque también se genera en los procesos de fabricación de pinturas y en fundidoras. La norma establecida como un nivel permisible es un promedio trimestral de $1.5 \mathrm{pg} / \mathrm{m}^{3}$.

En 1988 se sobrepasó la norma del nivel de plomo en nueve estaciones de monitoreo. A partir de 1989 se reduce el nivel del contaminante, tal como se observa en el cuadro 4. En esta dirección, se puede afirmar que de 1989 a 1992 las concentraciones de plomo se redujeron en alrededor de $90 \%$, hasta llegar a una tercera parte del límite de $1.5 \mu \mathrm{g} / \mathrm{m}^{3}$ en el último año (Comisión Metropolitana, marzo, 1995: 11). En forma semejante, si en 1989 se sobrepasó la 
norma en promedio $31.8 \%$ de los días, en 1993 y 1994 esta cifra disminuyó a cero (véase el cuadro 4). La drástica reducción de los niveles de plomo en la atmósfera se ha debido fundamentalmente a la política de sustitución de gasolinas, como se verá en la siguiente sección.

\section{La problemática ambiental en su conjunto}

Puede concluirse que entre 1986 y 1994 se logró reducir el nivel de contaminación atmosférica por plomo $(\mathrm{Pb})$, y tanto el monóxido de carbono $(\mathrm{CO})$ como el bióxido de azufre $\left(\mathrm{SO}_{2}\right)$ permanecieron estables y bajo la norma. Sin embargo, se observan elevados y crecientes niveles de Ozono $\left(\mathrm{O}_{3}\right)$, mientras que el bióxido de nitrógeno $\left(\mathrm{NO}_{2}\right)$ y las partículas suspendidas totales (PST) mantienen magnitudes considerables, por lo que la situación ambiental de la urbe está lejos de ser resuelta satisfactoriamente.

La mejoría relativa experimentada fue posible por los considerables esfuerzos gubernamentales realizados a partir de $\mathbf{1 9 8 9}$, que se verán en la sección correspondiente a "insuficiencia de las políticas anticontaminantes" de este trabajo, pero éstos están lejos de resolver la problemática en su conjunto. Ante esta situación cabe preguntarse: ¿qué pasará en el largo plazo si continúa el crecimiento de la ciudad de México y se transforma en un conglomerado megalopolitano que incorpore las áreas metropolitanas de Toluca, Cuernavaca, Puebla y Querétaro?

\section{Los determinantes de la contaminación: fuentes fijas y móviles}

Las partes por millón y los microgramos por metro cúbico en que se miden los contaminantes, por el gran volumen en que éstos se expiden en la atmósfera suman millones de toneladas anuales de productos tóxicos. En la ciudad de México se estima que en 1989 se emitieron 4.4 millones de toneladas de contaminantes atmosféricos producidos en forma diferencial por vehículos (fuentes móviles) y empresas industriales y comerciales (fuentes fijas). El crecimiento de las emisiones de ambas fuentes depende de la dinámica demográfica y económica de la capital mexicana; su actual superconcentración constituye el determinante fundamental de la magnitud alcanzada por la contaminación atmosférica.

Del último inventario de emisiones realizado en 1989, destaca que las fuentes móviles agrupadas en el sector transporte aportan $76.7 \%$ de la contaminación total, $14.9 \%$ la degradación ecológica y 
$8.4 \%$ restante la industria, servicios y energía (véase el cuadro 5). Los vehículos de combustión interna constituyen, por ende, la fuente principal de la contaminación atmosférica de la ciudad de México, aunque su importancia varía considerablemente según el tipo de contaminantes, puesto que originan $96.7 \%$ del monóxido de carbono y únicamente $2.1 \%$ de las partículas suspendidas totales (véanse el cuadro 5 y la gráfica 2).

\section{GRÁFICA 2}

Ciudad de México: inventario de contaminantes por sector (porcentajes)

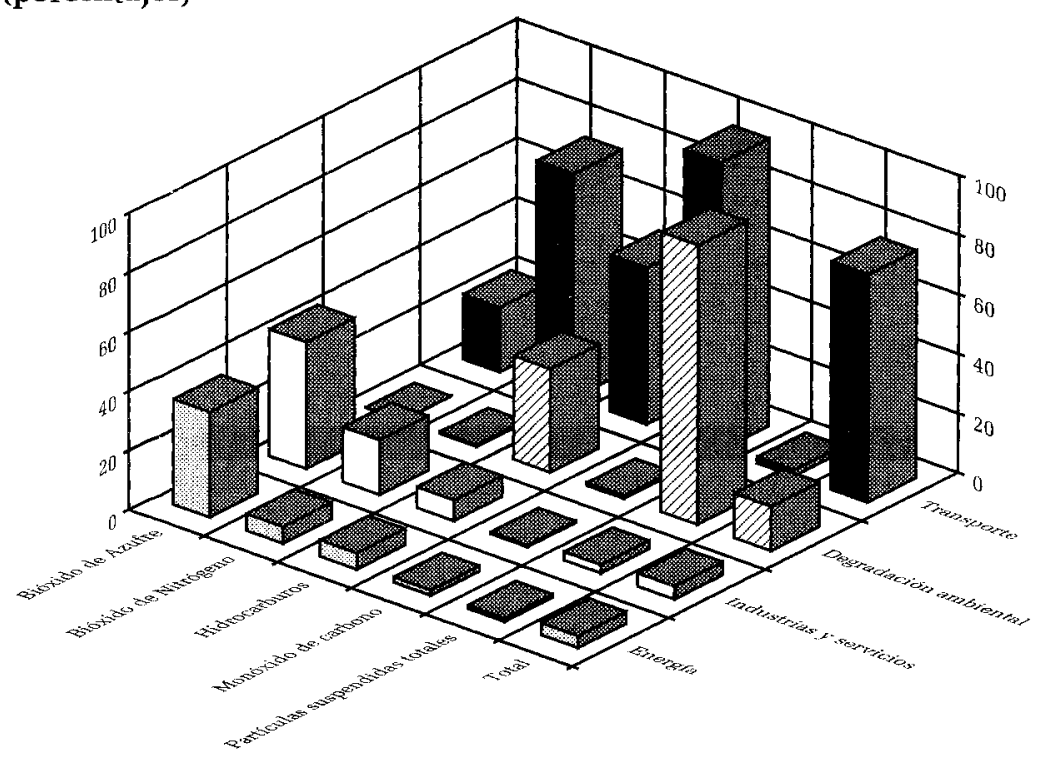

Fuente: cuadro 5 .

Las fuentes fijas sólo producen $8.4 \%$ de la contaminación total, pero sus emisiones representan $78.2 \%$ del bióxido de azufre (35.5\% el sector energía y $42.7 \%$ el industrial y servicios) y $24.0 \%$ de los óxidos de nitrógeno. Finalmente, la degradación ecológica es responsable de $93.1 \%$ de las partículas suspendidas totales y de $34.9 \%$ de los hidrocarburos. En síntesis, aunque en la ciudad de México la batalla principal en la lucha contra la contaminación atmosférica se centra en los vehículos de combustión interna, no es desdeñable la importancia del control de las plantas industriales y establecimientos de servicios y la regeneración ecológica. 


\section{Fuentes móviles}

En 1994 circulaban en la ciudad de México 3 millones de vehículos que usaban diferentes clases de combustibles. ${ }^{3}$ Los autos privados representan $94.5 \%$ con un total de 2859000 unidades; los colectivos y taxis $5 \%$ con 151000 unidades y los autobuses urbanos y suburbanos $0.4 \%$ con 12100 unidades. En el Distrito Federal, la tasa de motorización (número de automóviles por 100 habitantes) se incrementó de 2.0 en 1940 a 14.9 en 1987, y se estima de 20.0 en 1994, lo que ha provocado una creciente congestión vehicular en las principales avenidas debido a la inadecuación del sistema vial.

En este parque vehicular se realizan alrededor de 30 millones de traslados de personas diariamente (incluyendo transferencias), de los cuales 25 millones se efectúan utilizando el transporte público. Cerca de $75 \%$ de todos los viajes se originan en el Distrito Federal y tienen como destino el interior de éste, los municipios conurbados del Estado de México y, en menor medida, los estados de Puebla, Morelos, Hidalgo y Tlaxcala. Se estima que en 1990 se realizaron diariamente cerca de 4.4 millones de viajes en automóviles privados, lo que corresponde a $16 \%$ del total de traslados (Fernández, 1993).

Las emisiones de contaminantes generados por las fuentes móviles se calculan con base en el consumo de gasolinas, la flota vehicular que circula en la ciudad de México y los kilómetros anuales recorridos.

Entre 1989 y 1993 el consumo de gasolina en la ciudad de México creció a una tasa anual de $4.5 \%$, al pasar de 34.7 a $41.5 \mathrm{mi}$ llones de barriles (véase el cuadro 6). Considerando constante la emisión de contaminantes por vehículo, sería lógico esperar que al aumentar el consumo de gasolina se eleve la magnitud de la contaminación. Sin embargo, en estos cinco años ocurrió un cambio significativo en el tipo de gasolina utilizada, pues mientras que en $1989,97.5 \%$ era gasolina con plomo (Nova) y $2.5 \%$ sin plomo (Extra o Magna Sin), para 1993 el consumo de esta última se elevó a $29.4 \%$ (véanse el cuadro 6 y la gráfica 3). Esta política de sustitución de gasolina explica la reducción observada en los niveles de plomo en la atmósfera analizada en el apartado anterior, por lo que será necesario continuar la misma medida hasta eliminar el consumo de gasolina con plomo.

${ }^{3}$ Estimación a partir de la cifra de 2.5 millones en 1992, suponiendo que la tasa de crecimiento nacional en el número de vehículos es de $9.8 \%$. La cantidad de 1992 se obtuvo de Fernández (1993) y la distribución por tipo de unidades se realizó según la distribución presentada por este autor. 


\section{CUADRO 6}

Ciudad de México: consumo de combustible, 1989-1993

\begin{tabular}{|c|c|c|c|c|c|c|}
\hline \multirow[b]{2}{*}{ Año } & \multicolumn{2}{|c|}{ Extra o magna a } & \multicolumn{2}{|l|}{ Nova $\mathrm{b}$} & \multirow[b]{2}{*}{ Total } & \multirow[b]{2}{*}{$\%$} \\
\hline & Barriles & $\%$ & Barriles $\mathrm{c}$ & $\%$ & & \\
\hline 1989 & 866731 & 2.50 & 33882821 & 97.5 & 34749552 & 100.00 \\
\hline 1990 & 2065849 & 5.60 & 34694213 & 94.4 & 36760062 & 100.00 \\
\hline 1991 & 2215526 & 5.70 & 36818689 & 94.3 & 39034215 & 100.00 \\
\hline 1992 & 6802738 & 17.20 & 32835183 & 82.8 & 39637921 & 100.00 \\
\hline 1993 & 12202497 & 29.40 & 29275984 & 70.6 & 41478481 & 100.00 \\
\hline
\end{tabular}

Fuente: Comisión Metropolitana para la Prevención y Control de la Contaminación Ambiental en el Valle de México.

a Gasolina sin plomo.

b Gasolina con plomo.

c Un barril es igual a 159 litros.

\section{GRÁFICA 3}

Ciudad de México: consumo de gasolina con y sin plomo, 1989-1993 (porcentajes)

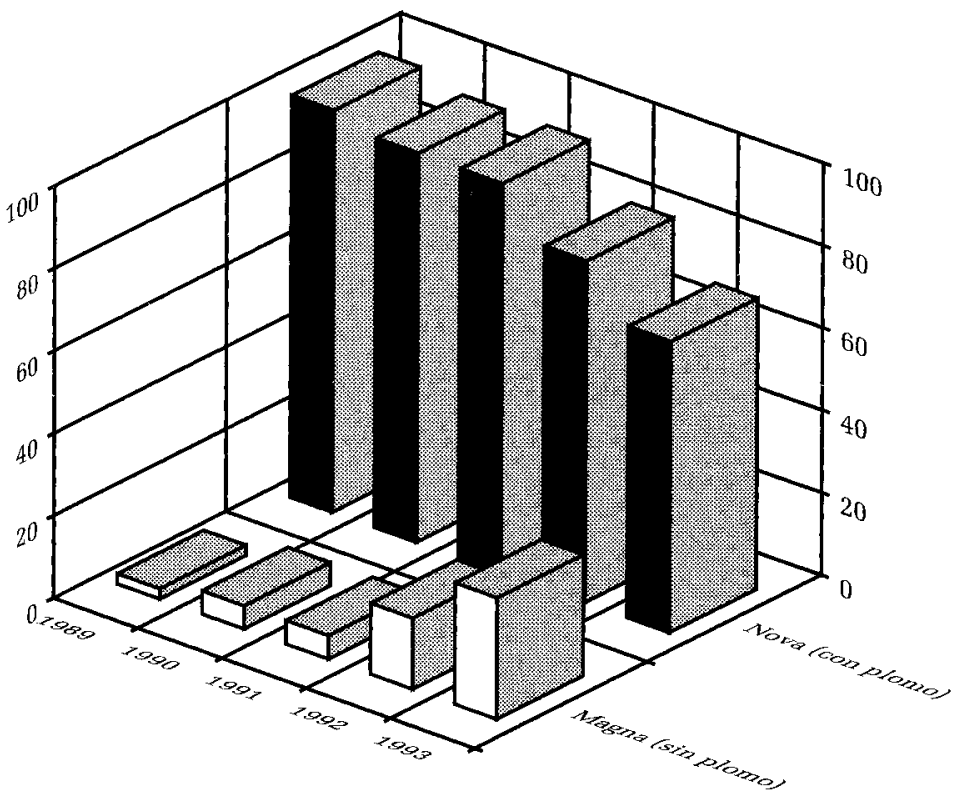

Fuente: cuadro 6. 
Al aumentar la emisión de hidrocarburos y óxidos de nitrógeno, precursores del ozono, la mejora en la calidad de la gasolina no ha evitado el incremento de los niveles de este último contaminante. ¿Qué ocurrirá en los próximos quince años cuando al menos se duplique el consumo de gasolina en la ciudad de México?

\section{Fuentes fijas}

En 1990 en la ciudad de México existían más de 30 mil establecimientos industriales; $72 \%$ se localizaron en el Distrito Federal y $28 \%$ en los municipios conurbados del Estado de México; $75 \%$ eran microindustrias, $20 \%$ pequeñas industrias, $3 \%$ medianas y $2 \%$ restante, grandes industrias. Se considera que alrededor de 4000 de estas plantas son las principales generadoras de contaminantes, por su tamaño y la naturaleza de su proceso productivo (Comisión Metropolitana, 1992). Además, en la ciudad de México existían en 1988 más de 282000 establecimientos comerciales y de servicios, algunos de los cuales emiten contaminantes: 13.9 mil empresas de aseo y limpieza, entre las que se encuentran las lavanderías, y 9.2 miles de salud, hoteles y asistencia social donde destacan hospitales (Garza, 1989a). No existe ningún censo que registre todos los giros industriales y sus emisiones contaminantes, en cierta medida por el gran número de microindustrias y pequeñas industrias. Sin embargo, la Comisión Metropolitana para la Prevención y Control de la Contaminación Ambiental en el valle de México ha estimado los niveles aproximados y tipos de contaminantes de las empresas, identificando los giros que más contaminan: refinerías, industrias químicas, petroquímicas, fundidoras, plantas de extracción de minerales no metálicos, industrias del papel, aluminio, cobre y metalúrgicas. Este tipo de empresas se localiza predominantemente al norte y oriente de la ciudad de México, aunque la farmacéutica y textil lo hacen en el centro y sur. En relación con los sectores económicos destaca que la industria es el principal contaminante de las fuentes fijas con $30.5 \%$ del total de emisiones, seguida por las termoeléctricas con $26.7 \%$ y, en tercer lugar, las actividades comerciales y de servicio, con la inclusión del lavado en seco, que generan 14.3\% (véase el cuadro 7).

En la ciudad de México la industria, la generación de electricidad y los servicios consumieron en 1991 más de 3.4 millones de barriles de diesel especial, 6.8 millones de barriles de combustóleo y 480000 de gasóleo industrial. El diesel especial que se distribuye en el valle de México desde mayo de 1986 posee $34 \%$ menos 
CUADRO 7

Ciudad de México: distribución porcentual de emisiones totales por fuentes fijas

\begin{tabular}{lc}
\hline Sectores económicos & Porcentaje \\
\hline Industria & 30.5 \\
Termoeléctrica & 26.7 \\
Comercio y servicio & 11.2 \\
Revestimientos & 9.0 \\
Procesamiento de minerales & 8.8 \\
Industria química & 5.1 \\
Procesamiento de metales & 3.3 \\
Lavado en seco & 3.1 \\
Impresiones & 1.1 \\
Desengrasado industrial & 0.8 \\
Papel y madera & 0.4 \\
Total & 100.0 \\
\hline
\end{tabular}

Fuente: Comisión Metropolitana para la Prevención y Control de la Contaminación Ambiental en el Valle de México, Programa para el control de emisiones de contaminantes atmosféricas de la industria en la Zona Metropolitana de Ia Ciudad de México, versión preliminar, 1992: 17.

azufre que el del resto del país. A partir de diciembre de 1991 la compañía Petróleos Mexicanos (Pemex) cambió el suministro de combustóleo por gasóleo industrial en el valle de México, que contiene $33 \%$ menos azufre, $60 \%$ menos de nitrógeno y elimina $99 \%$ del vanadio, níquel y diversos elementos. Adicionalmente, en 1992 se consumían 150 millones de pies cúbicos de gas más que en 1990, debido al cambio de combustóleo por gasóleo en las industrias. Dado que el gas no contiene azufre, esta medida ha permitido reducir la emisión a la atmósfera de bióxido de azufre.

Las acciones anteriores tienen que ser complementadas con cambios al interior de las empresas industriales, pues las inspecciones que se realizan indican que muchas aún no han instalado equipos de control de emisiones o, cuando los tienen, son obsoletos y sin mantenimiento adecuado (Departamento del Distrito Federal, 1991).

En el futuro, la contaminación atmosférica generada por las plantas industriales y las actividades comerciales y de servicio en la ciudad de México dependerá de sus perspectivas de crecimiento económico y del grado en que se cumplan las disposiciones sobre instalación de equipos anticontaminantes y la observancia de las normas oficiales mexicanas. 
La importancia de la ciudad de México en la industria nacional ha sido creciente, pues ha logrado elevar su participación de $32.1 \%$ del producto interno bruto (PIB) en 1940 a $43.3 \%$ en 1980. Sin embargo, durante la aguda crisis económica de los años ochenta, la capital del país fue la ciudad más afectada, al reducir su producción industrial en términos absolutos entre 1980-1988 y desplomar a $32.1 \%$ su participación del total nacional. A partir de 1989 se inició cierta recuperación económica cuando el PIB nacional creció a $3.3 \%$, a $4.4 \%$ en $1990,3.6 \%$ en 1991 , y $2.8 \%$ en 1992 , pero su descenso a $0.4 \%$ en 1993 hace temer una nueva recesión.

La entrada en vigor del Tratado de Libre Comercio (TLC) entre Canadá, Estados Unidos y México en enero de 1994 auguraba la recuperación, pero pasado el primer semestre de su operación aún no se observaban síntomas de que pudiera iniciarse la reactivación de la economía nacional. Sea como fuere, es incuestionable que el futuro económico de México dependerá en gran medida de la evolución del TLC. Aunque se presume que un desarrollo exitoso del Tratado significará el estímulo de las ciudades del norte de México y el freno al crecimiento de la capital del país, ésta continuará con su proceso de consolidación megalopolitana creciendo en magnitudes significativas y acentuando el deterioro ecológico de su ecosistema.

\section{Contaminación atmosférica y salud de la población}

La ciudad de México es de las más contaminadas del mundo, pero el riesgo que esto implica para la salud de sus habitantes no se conoce con precisión. En principio, cuando las personas se exponen a contaminantes atmosféricos superiores a las normas establecidas pueden existir efectos nocivos para su salud. Esto ocurre claramente con los niveles de ozono en la ciudad de México, pero no existen investigaciones suficientes para determinar el grado de riesgo o si es posible desarrollar mecanismos inmunológicos para tolerar dicha agresión sin problemas clínicos detectables (Castillejos, 1992). En general, se considera difícil conocer los efectos de los contaminantes sobre la salud por la complejidad de demostrar la relación entre la afección y el contaminante dentro de un sistema de relaciones sinérgicas que resulta complicado de descubrir y medir.

En la ciudad de México, adicionalmente, es frecuente encontrar diferencias en las concentraciones de los diversos tipos de contaminantes que hacen más complejo estudiar su relación con la salud. Mientras los habitantes de la zona suroeste están permanentemente expuestos a altos niveles de ozono, los que vi- 
ven en el noreste lo están a una mezcla no bien determinada de hidrocarburos, ozono, bióxido de azufre y altas concentraciones de partículas. Los habitantes del centro en algunas ocasiones sufren altos niveles de ozono y, en otras, de óxidos de nitrógeno y partículas.

En los últimos años, la investigación en torno a los efectos que produce en la salud la exposición cotidiana a este tipo de sustancias tóxicas ha cobrado gran importancia, sobre todo las caracterizaciones acerca de su potencial toxicológico. Se sabe, no obstante, que los organismos pueden tener una variedad de reacciones patológicas, tales como la reducción en su crecimiento, alteraciones reproductivas, cambios conductuales e incluso la muerte (Moreno Sánchez, 1991). En México, la mayoría de los investigadores que estudian el impacto de los contaminantes atmosféricos en la salud han centrado su atención en los efectos que produce el plomo en el desarrollo de los niños y han analizado las consecuencias respiratorias del ozono en niños asmáticos. Se encontró, por ejemplo, que en tres escuelas primarias de la ciudad de México los niños presentaron variaciones en las tasas de morbilidad de enfermedades respiratorias; las más altas se registraron en el suroeste, donde existen los mayores niveles de ozono (Castillejos, 1992). Otros estudios realizados con escolares de diferentes estratos socioeconómicos de la misma zona demostró que existe una asociación entre niveles altos de ozono y disminución de la función respiratoria. Sin embargo, con estas investigaciones no es posible precisar las consecuencias en la salud de toda la población a lo largo del tiempo y durante el desarrollo de sus actividades.

También existen estudios que abordan los riesgos de la exposición al monóxido de carbono, entre los que destaca uno muy reciente (Fernández, 1993). Este trabajo demuestra que los valores obtenidos de monóxido de carbono en las estaciones de monitoreo no representan los niveles a los cuales las personas están expuestas dentro de los vehículos y en las calles, por lo que la distribución espacial y la dinámica ambiental del monóxido de carbono requiere ser analizada con mucha mayor profundidad.

En síntesis, en el caso de la ciudad de México son muy incipientes las investigaciones de los efectos de la contaminación atmosférica sobre la salud de sus habitantes; además, la información epidemiológica correspondiente es muy escasa (Santos-Burgoa y Rojas Bracho, 1992). Los estudios futuros tendrán que profundizar en el conocimiento de la naturaleza de las fuentes contaminantes y la posibilidad real de reducir sus emisiones, los niveles de exposición, los aspectos toxicológicos asociados a cada conta- 
minante y, en general, las características de la dinámica ambiental ante la expansión de la urbe.

\section{Insuficiencia de las políticas anticontaminantes}

En 1986 se estableció un primer programa tendiente a reducir la contaminación atmosférica en la ciudad de México denominado "Decreto de febrero 14". Su propósito principal era aminorar las elevadas emisiones de contaminantes atmosféricos del descuidado transporte público automotor, planteando la necesidad de renovarlo con autobuses que tuvieran un mejor motor, de suministrar gasolina con menor contenido de plomo y diesel con menos .azufre, así como el continuar desarrollando el sistema de transporte eléctrico de trolebuses, metro y tren ligero.

El impacto real de esta iniciativa fue reducido y no incidió directamente sobre la magnitud y flujos del automóvil privado. La aparición de este programa, sin embargo, marca el inicio de una serie de acciones rigurosas contra el deterioro ambiental de la capital de la República.

Al año siguiente se implementó un programa de mejoramiento ambiental más ambicioso de nivel nacional: "Las 100 acciones necesarias". Esta iniciativa tenía como objetivo llevar a cabo un mayor control de las emisiones contaminantes, para lo cual estableció estándares más estrictos para las emisiones de los vehículos nuevos, modelo 1988, así como la inspección y mantenimiento (l/M) de las unidades de los años 1977 a 1982, y la verificación vehicular dos veces al año de 2.7 millones de vehículos, incluyendo los de motor diesel.

No obstante la importancia de la iniciativa, la l/M presentó serias limitaciones debido a la falta de un método estandarizado de verificación y porque durante la inspección se cometían irregularidades, de tal suerte que de una forma u otra prácticamente todos los vehículos la aprobaban. Sea como fuere, el programa logra que los vehículos estén mejor afinados y su motor en razonables condiciones. Adicionalmente, en sus años de vigencia esta iniciativa se ha ido perfeccionando y en 1993 empezó a emplear analizadores automatizados y personal entrenado en los talleres mecánicos que form an parte del programa.

Cuando se empezó a implementar la l/M, las autoridades estimaban una reducción del monóxido de carbono de $20 \%$, y de $15 \%$ para los hidrocarburos (Fernández, 1993). Un pronóstico más conservador señalaba una disminución de $10.7 \%$ y $6.1 \%$, respectivamente, sin precisar el plazo. 
En noviembre de 1989 se implementó un programa de contingencia denominado "Un día sin auto", el cual se pretendía aplicar para la temporada de invierno 1989-1990,4 pero se convirtió en un programa permanente. " "Un día sin auto" consiste en prohibir la circulación de los automóviles un día a la semana para reducir las emisiones. Sin embargo, el consumo de combustible en los primeros meses decreció solamente $6 \%$ con respecto al año previo (Fernández, 1993). Posteriormente, empezó a elevarse a una tasa promedio de $4.5 \%$ anual entre 1989 y 1993 , como se vio anteriormente. Esto ocurrió, en buena medida, por el incremento en el número de viajes que las personas hacían cuando su vehículo podía circular, el mayor uso de taxis y el incremento en la venta de automóviles nuevos para poder circular todos los días. En 1994 "un día sin auto" ya tenía cinco años continuos de vigencia, que significaban la prohibición de circular para 600000 vehículos diariamente, lo cual no impidió el aumento en el con* sumo de gasolina y los niveles de contaminación. Ha sido simple, a pesar de su complejidad práctica, intentar modificar por decreto las necesidades de traslado de los millones de habitantes de la ciudad de México a sus empleos, escuelas, lugares de compra y de amenidades. El programa se encuentra en un callejón sin salida, pues no produjo los resultados esperados, y será totalmente contraproducente permitir la liberación de los 600 mil vehículos cautivos diariamente.

La Comisión Metropolitana Ambiental en el Valle de México inició en 1990 la implementación de un programa de cinco años con un costo de 3000 millones de dólares con el propósito de abatir drásticamente las emisiones contaminantes: el Programa Integral contra la Contaminación Atmosférica de la Zona Metropolitana de la Ciudad de México (PICCA).

El PICCA se centra en aspectos relacionados con la tecnología de automóviles y combustibles y el desarrollo del transporte, estimulando la producción de gasolina sin plomo; la reducción del contenido de azufre en el diesel (de 5 a $0.1 \%$ ) y en la gasolina (de $4 \%$ a $0.8 \%$ ); el aumento en la red de transporte colectivo, como el Metro y el trolebús; el reemplazo de toda la flota de autobuses públicos (Ruta 100) por 3500 unidades nuevas; la extensión del programa I/M a los vehículos de diesel; la conversión a gas de camiones de carga; la instalación de convertidores catalíticos en todos los taxis

\footnotetext{
4 Este programa es también conocido como "hoy no circula".

5 En 1987 se había promovido un programa voluntario de "no circula", que fracasó por la poca colaboración de los automovilistas.
} 
y colectivos; los incentivos fiscales y crediticios para que las industrias instalen equipo anticontaminante; la sustitución de combustóleos por gas natural en plantas generadoras de energía para reducir la liberación de azufre; la reforestación de áreas periféricas de la ciudad para constituir un gran cinturón verde y, finalmente, promover la investigación sobre la problemática ambiental. 6

Las autoridades estimaron que con la completa implementación del PICCA en 1995, se reducirían las emisiones contaminantes en relación con 1989: en $36 \%$ el monóxido de carbono, $79 \%$ el bióxido de azufre, $26 \%$ los hidrocarburos, $55 \%$ las partículas suspendidas totales, $5 \%$ los dióxidos de nitrógeno y $40 \%$ el plomo.

La más reciente iniciativa en la lucha para abatir la contaminación es el Programa de Verificación Industrial que inició en marzo de 1992; plantea la reducción, en un plazo de año y medio, de 90\% de las emisiones de compuestos orgánicos volátiles, $90 \%$ de partículas suspendidas y $50 \%$ de los bióxidos de nitrógeno expedidos por las plantas industriales. La Comisión Metropolitana realiza desde entonces el seguimiento de los compromisos contraídos por el sector industrial. En 1993, además el Reglamento de Prevención y Control de la Contaminación de la Atmósfera estableció cinco normas que especifican los niveles máximos permisibles de los contaminantes provenientes de las empresas industriales y 23 procedimientos de muestreo y cuantificación de emisiones (INE, 1993). También presenta para los vehículos ocho normas sobre los niveles máximos permisibles de emisión de hidrocarburos, monóxido de carbono y óxidos de nitrógeno.

A pesar de los notables esfuerzos que ha significado este conjunto de programas, se ha visto que los resultados obtenidos no son satisfactorios debido, a nuestro parecer, a tres razones principales: i) están descontextualizados de la dinámica global de la

${ }^{6}$ Entre el 1 de diciembre de 1992 y el 31 de marzo de 1993 se aplicaron 11 medidas adicionales a las incluidas normalmente en el PICCA: la reformulación de las gasolinas; el abastecimiento de diesel especial en el interior del país a aquellos camiones que tengan como destino la ciudad de México; la reducción de $25 \%$ en el consumo de combustibles en las termoeléctricas de la ciudad de México durante el periodo invernal para reducir las emisiones de bióxido de nitrógeno; la vigilancia aérea diaria para detectar la quema de materiales a cielo abierto, así como emisiones industriales y de establecimientos de servicio ostensiblemente contaminantes; el reforzamiento del programa de verificación industrial (se llevaron a cabo 200 inspecciones mensuales entre agosto y noviembre de 1992, y 1100 entre diciembre y marzo de 1993); el retiro de vehículos ostensiblemente contaminantes; la modernización del Programa de Verificación Vehicular; el reforzamiento de las acciones del Sistema Nacional de Salud para la identificación de los efectos de los contaminantes en la salud mediante vigilancia epidemiológica; la exención del "Hoy no circula" al transporte escolar y de trabajadores, y la promoción en el uso del transporte colectivo. 
metrópoli; ii) presentan limitaciones técnicas, y iii) han sido implementados apresurada y tardíamente.

Rebasa con mucho las posibilidades de este documento analizar detalladamente las anteriores limitaciones, por lo que solamente se ejemplifican en forma sucinta. En primer lugar, el crecimiento de las fuentes fijas y móviles es consustancial a la dinámica de la ciudad, por lo que además de regular su funcionamiento será necesario limitar el aumento en su número. Han sido, por tanto, contradictorios con las políticas ecológicas los programas de estímulo económico por medio de la creación de parques industriales y grandes centros comerciales en la ciudad. Esta desarticulación es evidente considerando que en el periodo 1988-1994 se realizó el PICCA y otros programas ecológicos, pero no se elaboró ningún plan global de desarrollo urbano para una de las urbes más complejas del planeta.

En segundo lugar, como resultado del desconocimiento de la dinámica atmosférica, los efectos sinérgicos y la formación de contaminantes secundarios, las acciones anticontaminantes condujeron al cambio de una atmósfera con características reductoras a una de tipo oxidante. Efectivamente, al parecer no se contemplaron los efectos directos en la emisión de hidrocarburos reactivos resultantes del cambio en la formulación de las gasolinas y de la sustitución del combustóleo por el gas natural. En efecto, se logró reducir las emisiones de plomo y bióxido de azufre, pero no de los óxidos de nitrógeno e hidrocarburos, transformando la atmósfera en oxidante (Bravo, 1992). Esto explica los crecientes niveles de ozono en la atmósfera de la ciudad.

Finalmente, habiéndose planteado claras advertencias sobre la creciente contaminación atmosférica de la ciudad de México desde inicios de los años setenta, pasaron más de 15 años antes de que se iniciaran acciones al respecto. La gravedad alcanzada por los niveles de contaminación y la carencia de un aparato técnico-administrativo adecuado, explica la insuficiencia de estas acciones y la realización de otras políticas de estímulo económico que resultan contraproducentes desde la perspectiva de un desarrollo metropolitano sustentable.

Concentración megalopolitana: ¿colapso en cadena de ecosistemas?

En las postrimerías del siglo Xx, los sistemas urbanos más avanzados se transforman en tejidos policéntricos que concentran estructuras y relaciones sociales más complejas, constituyendo sub- 
sistemas integrados de ciudades que se denominan megalópolis cuando surgen del traslape de dos o más áreas metropolitanas. En el nivel mundial, ejemplos de estos conglomerados son las megalópolis Tokaido, en Japón, y la de Nueva York, en la costa este de Estados Unidos.

A partir de 1980 el Área Metropolitana de la Ciudad de México se traslapó con la de Toluca al incorporar indistintamente al municipio de Huixquilucan, por lo que se constituyó una superficie megalopolitana que se puede denominar Megalópolis de la Ciudad de México. En 1990 el Área Metropolitana de la Ciudad de México (AMCM) tenía 15 millones de habitantes distribuidos en las 16 delegaciones del Distrito Federal y 27 municipios del Estado de México, y la de Toluca contaba con 827000 localizados en cinco municipios. En 1990 esta incipiente megalópolis tenía alrededor de 16 millones de personas, e inició un proceso de elevada interacción ejemplificada por la construcción del centro comercial Santa Fe, inaugurado en 1993 y considerado el más grande de América Latina; está localizado al poniente de la ciudad de México, a sólo 20 minutos del oriente de Toluca. En 1994 se estimaba que el AMCM tenía 16.8 millones y la de Toluca un millón, acercándose a los 18 millones de habitantes como conjunto megalopolitano. ${ }^{7}$

A esta megalópolis emergente se le agregarán en las próximas décadas el Área Metropolitana de Cuernavaca, ciudad de 450000 habitantes localizada a $70 \mathrm{~km}$ al sur de la ciudad de México, la de Puebla al oriente con 1.8 millones de habitantes en 1990 y la de Querétaro, al norte, con 385000 habitantes. En 1994 las áreas metropolitanas de la ciudad de México, Toluca, Cuernavaca, Puebla y Querétaro tenían en conjunto alrededor de 21 millones de personas, y se estima que habrá un mínimo de 25 millones en el año 2000 y 34 millones en el 2010.8 Dejando de lado los requerimientos de infraestructura y servicios urbanos que demandará la megalópolis y los problemas político-sociales que presente, importa reflexionar sobre el deterioro ambiental en sus ecosistemas.

7 La estimación del AMCM śe realizó considerando una población total nacional de 91222077 personas en 1994 a la cual se le aplicó $18.4 \%$ que la metrópoli tenía de la población total en 1990. La cifra de la población total nacional en 1994 se puede ver en Camposortega (1994). La de Toluca se estimó con base en la población total de 1990 y la tasa de crecimiento de 3.3\% experimentada entre 1980-1990.

${ }^{8}$ Estimación suponiendo una tasa anual de $3 \%$ del crecimiento demográfico de todo el conjunto megalopolitano. Esta tasa es razonable considerando que entre 1980-1990, Puebla créció a un ritmo de $4.6 \%$ anual, Cuernavaca de $4.9 \%$ y Querétaro de 5.9 por ciento. 
Las montañas, altitud y vientos dominantes del valle de México seguirán siendo factores que contribuyan a agravar su contaminación atmosférica, por lo que la posibilidad de atenuarla depende de que las fuentes móviles y fijas reduzcan significativamente sus emisiones. Durante $88.5 \%$ de los primeros 164 días de 1994 la norma establecida de ozono en la ciudad de México se sobrepasó. Ante esta situación, al crecer la flota actual de 3 millones de automóviles hasta un mínimo de 6.6 millones para el año 2010, se agudizarán los niveles de contaminación diaria amenazando seriamente la capacidad de autorregeneración del ecosistema de la urbe.

El deterioro de la atmósfera del valle de México se verá acompañado por el de los valles de las ciudades que lo rodean: el valle de Puebla, el valle de Toluca, el valle de Cuernavaca y el valle de Querétaro. En estas áreas habrá en el año 2010 alrededor de un millón de vehículos, parte de los cuales se trasladarán continuamente a la ciudad de México porque es el principal medio de transporte que las comunica.

La ciudad de México cuenta con mediciones sistemáticas de la contaminación atmosférica a partir de 1986, pero en algunas de las ciudades de su megalópolis se empezaron a prácticar hasta 1993. Sin embargo, a partir de 1988 Toluca dispone de información sobre partículas suspendidas totales (PST) que permite conocer la tendencia de su contaminación atmosférica, aunque los datos no sean del todo comparables.

En Toluca sólo en enero de 1988 se sobrepasó la norma de PST de $275 \mu \mathrm{g} / \mathrm{m}^{3}$ con $328.8 \mu_{\mathrm{g}} / \mathrm{m}^{3}$. Cinco años después, en 1993, en 10 meses del año se superó ampliamente dicha norma, siendo cuatro veces superior en mayo cuando las PST alcanzan la considerable cifra de $1114.3 \mu_{\mathrm{g}} / \mathrm{m}^{3}$ (véase el cuadro 8 ).

No se dispone de series históricas de contaminantes para los valles de Puebla, Cuernavaca y Querétaro, pero al parecer también están aumentando considerablemente su contaminación atmosférica, de suerte que existe la posibilidad real de que en las primeras décadas del siglo XXI se produzca un deterioro en cadena de los ecosistemas de los valles que conforman la megalópolis de la ciudad de México.

En los años setenta se advirtió oportunamente el inicio de un acelerado deterioro ambiental del ecosistema de la ciudad de México, pero la urbe continuó su camino de elevado crecimiento económico y demográfico sin que existiera preocupación por la dinámica de sus ecosistemas, hasta que los niveles de contaminación atmosférica llegaron a niveles críticos hacia finales de los años ochenta. El orgullo de construir una megaurbe que plasmara territorialmente el "milagro económico mexicano" del periodo 
CUADRO 8

Toluca: promedios mensuales de partículas sólidas totales, 1988 y 1993 $\left(\boldsymbol{\mu}_{\left.\mathrm{g} / \mathrm{m}^{3}\right)}\right.$

\begin{tabular}{lrr}
\hline & 1988 & 1993 \\
\hline Norma & 275.00 & 275.00 \\
Enero & 328.00 & 795.80 \\
Febrero & 248.70 & 933.60 \\
Marzo & 183.30 & 1001.50 \\
Abril & 151.60 & 417.70 \\
Mayo & 242.10 & 114.30 \\
Junio & 90.10 & 549.60 \\
Julio & 94.20 & 280.10 \\
Agosto & 68.70 & 220.00 \\
Septiembre & 106.20 & 207.10 \\
Octubre & 107.90 & 401.00 \\
Noviembre & 174.30 & 325.40 \\
Diciembre & 200.70 & $508.00^{*}$ \\
\hline
\end{tabular}

Fuente: Secretaría de Desarrollo Social. Subsecretaría de Protección Ambiental. Delegación Estado de México.

* No hubo medida en diciembre de 1993 y este valor corresponde a diciembre de 1992

1940-1980, se convierte en pesadumbre al resultar una de las ciudades más contaminadas del mundo. En los años noventa se constata que las políticas implementadas están lejos de resolver la elevada contaminación ambiental del valle de México y, lo que es más grave, se vislumbra nítidamente que el problema del medio ambiente será de una magnitud megalopolitana que implicará el deterioro en cadena de los valles de las ciudades vecinas de Toluca, Cuernavaca, Puebla y Querétaro.

A pesar de la gravedad de esta posibilidad, no existe plena conciencia del problema ambiental de la ciudad de México y de su megalópolis emergente, que amenaza con romper para siempre la armonía básica entre el ser humano y la naturaleza.

\section{Bibliografía}

Bárcenas Ibarra, Alicia (1984), "El hábitat urbano: deterioro y conservación", en El desarrollo urbano en México. Problemas y perspectivas, México, Programa Universitario Justo Sierra, UNAM, pp. 229-240. 
Bravo, Humberto (1973), Estudio comparativo y evaluación de la calidad del aire en la ciudad de México, México, Secretaría de Salubridad y Asistencia, enero.

- (1992), "La problemática de la contaminación atmosférica en la ZMCM. Legislación y posibles soluciones", ponencia presentada en el Primer Congreso y Exposición de la Industria y Medio Ambiente México-EUA, México.

Camposortega Cruz, Sergio (1994), "El monto de la población. 91 millones en 1994", en Demos, núm. 7, pp. 4-6.

Castillejos, Margarita (1992), "La contaminación atmosférica y la salud: algunas reflexiones sobre el tema", en La contaminación atmosférica en México. Sus causas y efectos en la salud, México, Comisión Nacional de Derechos Humanos.

Comisión Metropolitana para la Prevención y Control de la Contaminación Ambiental en el Valle de México (1992), Programa para el control de emisiones de contaminantes atmosféricos de la industria en la Zona Metropolitana de la Ciudad de México, México.

- (abril, 1993), Programa integral contra la contaminación atmosférica en la Zona Metropolitana de la Ciudad de México, medidas de invierno, 1992-1993, informe de actividades, México.

(diciembre, 1993), "Informe mensual de la calidad del aire", México.

(febrero, 1994), Programa integral contra la contaminación atmosférica en la Zona Metropolitana de la Ciudad de México, medidas de invierno, 1993-1994, informe de actividades, México.

___ (marzo, 1994), "Informe ejecutivo de la calidad del aire (19911993)", México.

Departamento del Distrito Federal (1991), Air Polution Control in the Mexico City Metropolitan Area, Results for the Short-term Program, Consolidated Draft Report, México.

Escobar, R. (1973), Las operaciones industriales como fuente de contaminación atmosférica, México, Secretaría de Salubridad y Asistencia.

Fernández, Adrián (1993), Commuters' Exposure to Carbon Monoxide in the Metropolitan Area of Mexico City, tesis de doctorado, Inglaterra, Centre for Environmental Technology, Imperial College of Science, Technology and Medicine, The University of London.

Garza, Gustavo (1987a), "El futuro de la ciudad de México: megalópolis emergente", en Gustavo Garza et al. (comps.), Atlas de la ciudad de México, México, Departamento del Distrito Federal/El Colegio de México. - (1987b), "Hacia la superconcentración industrial en la ciudad de México", en G. Garza et al. (comps.), Atlas de la ciudad de México, México, Departamento del Distrito Federal/El Colegio de México.

- (1989a), "The Crisis of the Service Sector in Mexico City, 19601990", conferencia presentada en Socio-Demographic Effects of the 1980's Economic Crisis in Mexico, Universidad de Texas en Austin. (1989b), "Mexico City: Spacial, Demographic and Economic Development, 1900-2010", en Bulletin of the International Statistical Institute, Proceedings of the 47th Session, Book 1, París. 
ngeniería y Gestión Ambiental (febrero, 1993), "Calidad del aire de la ciudad de México", reporte mensual, México, D.F.

instituto Nacional de Ecología, (1993), "Informe de la situación general en materia de equilibrio ecológico y protección al ambiente 19911992", México, Sedesol.

Lacy, Rodolfo (comp.) (1993), La calidad del aire en el Valle de México, México, El Colegio de México.

Márquez Mayaudón, E. (1978), "La contaminación ambiental en México", en Contaminación ambiental, Memoria de la Reunión Nacional sobre Problemas de Contaminación Ambiental, t. 1, México.

Moreno Sánchez, Ana Rosa (1991), "Ecología, contaminación y salud", en Información Científica y Tecnológica, vol. 13, núm. 173, pp. 31-35.

Ortiz Monasterio, F. (1991), Contaminación en la ciudad de México, México, Milenio.

Programa integral contra la contaminación atmosférica de la Zona Metropolitana de la Ciudad de México (1990), México, Secretariado Técnico Intergubernamental, octubre.

Rapoport, Eduardo e Ismael López-Moreno (1984), "Algunos problemas de la ecología urbana de la ciudad de México", en EI desarrollo urbano en México. Problemas y perspectivas, México, Programa Universitario Justo Sierra, UNAM, pp. 241-249.

SAHOP (1978), Diagnóstico de la calidad atmosférica del Valle de México, México, Subsecretaría de Asentamientos Humanos, Dirección General de Ecología Urbana.

Santos-Burgoa, Carlos y Leonora Rojas Bracho (1992), "Los efectos de la contaminación en la salud", en La contaminación atmosférica en México. Sus causas y efectos en la salud, México, Comisión Nacional de Derechos Humanos.

Streit, Gerald (1992), "México City Air Quality: Progress of an International Collaborative Project to Define Air Quality Management Options", en México City Air Quality Research Initiative, Technical Presentations, Nuevo Mexico, Los Alamos National Laboratory/Instituto Mexicano del Petróleo.

Vizcaíno Murray, F. (1975), La contaminación en México, México, Fondo de Cultura Económica. 
